\title{
Longitudinal study of family factors associated with risk behaviors in Mexican youth
}

\author{
Alejandro González-González', Diana Betancourt Ocampo', Héctor Romo-Parra', Héctor Fernández-Varela Mejía ${ }^{2}$ y \\ Cuauhtémoc Solís Torres ${ }^{2}$ \\ I Universidad Anáhuac México-Norte, México \\ 2 Universidad Nacional Autónoma de México, México
}

\section{RESUMEN}

Introducción: de acuerdo con la literatura, la adolescencia es un periodo en el que los jóvenes tienen mayores probabilidades de involucrarse en actividades que podrían poner en riesgo su salud. Además, existe evidencia que sugiere el impacto de algunos factores del ambiente familiar en el involucramiento en diversas conductas de riesgo. Objetivo: determinar los cambios en las conductas de riesgo, así como analizar las diferencias en los factores familiares asociados con las mismas. Metodo: se realizó un estudio longitudinal en jóvenes universitarios. Participaron 6,089 estudiantes (37.5\% hombres y $62.5 \%$ mujeres). Las conductas de riesgo fueron evaluadas con 10 indicadores; los factores familiares se evaluaron con tres escalas: apoyo familiar, relación familiar y abuso de sustancias dentro del contexto familiar. La recopilación de la información se realizó en una sesión previa al inicio del semestre en los tres momentos analizados. Resultados: se observó un incremento en la presencia de las conductas de riesgo a través del tiempo, así como diferencias significativas en los factores familiares por el número de conductas de riesgo en las tres mediciones. Discusión: esta evidencia permitirá el desarrollo de programas de prevención y detección temprana para tratar varios problemas relacionados con los adolescentes durante su trayectoria escolar.

\begin{abstract}
Introduction: according to literature, adolescence is a period where the young are more likely to engage in behaviors that could endanger their health. In addition, there is evidence suggesting the impact of some factors of family environment on the presence of risk behaviors. Objetive: the aim of this study was to determine changes in risk behavior and analyze the differences in family factors on these behaviors. Method: we used a longitudinal study on a group of 6,089 students $(37.5 \%$ men and $62.5 \%$ women). Risk behaviors were assessed with 10 indicators. Family factors were evaluated by three scales: support, relationship and substance abuse within the family context. The information was obtained in a previous session prior to the beginning of the scholar semester for each of the three analyzed events. Results: an increase in risk behaviors was observed over time. Further, we also found significant differences in family factors on risk behaviors in the three measurements. Discussion: this evidence will allow the development of prevention and early detection programs to treat several problems related to teenagers during their school career.
\end{abstract}

Keywords: longitudinal study, family, risk behavior, youth, students.

Palabras clave: estudio longitudinal, familia, conductas de riesgo, jóvenes, estudiantes.

\section{Corresponding author:}

Diana Betancourt Ocampo. Universidad Anáhuac México-Norte. Av. Universidad Anáhuac, núm. 46, col. Lomas Anáhuac, Huixquilucan, Estado de México, C.P. 52786. Tel. +52 (55) 56270210 ext. 8495. Correo electrónico: diana.betancourt@anahuac.mx Recibido: 24 de febrero de 2017.

Aceptado: 18 de abril de 2017.

DOI: $10.28931 /$ riiad.2017.1.02 


\section{INTRODUCTION}

The dominant concept of adolescent development, identifies this stage of life as a turbulent period of stress, or as a stage where a disturbance of regulatory human development arises (Lerner, 2005). In this sense, it is associated with conflicts between teenagers and their parents, emotional outbursts and moodiness. However, this characterization of adolescence may be more a description of early adolescence and the transition from childhood to adolescence, rather than a representation of the entire process (Hines \& Paulson, 2006; Wijsbroek, Hale, Van Doorn, Raaijmaker, \& Meeus, 2010).

In Mexico, according to the National Health and Nutrition Examination Survey 2012 (Ensanut, for its acronym in Spanish; Gutierrez et al., 2012) risk behaviors and their consequences influence the health of adolescents; this behaviors include accidents, substance abuse, violence, early start on sexual activity, unprotected sex, sexually transmitted infections, among others. Regarding sexual behavior, Ensanut 2012 indicates that $23 \%$ of the teenagers have started their sexual life, of which, $14.7 \%$ of men and $33.4 \%$ of women reported not using birth control. Of the adolescents who reported using contraception, the condom was the most popular method (80.6\%), followed by hormonal methods (6.2\%).

The National Survey of Addictions (ENA) in 2011 reported that $12.3 \%$ of Mexican adolescents (12-17 years) have used tobacco, with an average age of first use of 14.1 years and average cigarette consumption per day of 4.1 (Instituto Nacional de Psiquiatría Ramón de la Fuente Muñiz [INPRFM], Instituto Nacional de Salud Pública [INSP], \& Secretaría de Salud [SS], 2012c). The results of this survey indicate, also, that $42.9 \%$ of teenagers have consumed alcohol at least once in their life, 30\% last year and $19.5 \%$ in the last month; the average age of first use was 17.7 years (INPRFM, INSP, \& SS, 2012a). Likewise, on the consumption of illegal drugs, data indicates that $1.5 \%$ of adolescents in México have used, at least, one illegal drug. The preference drugs are: marijuana $(1.37 \%)$, cocaine (.4\%) and inhalants (.3\%) (INPRFM, INSP, \& SS, 2012b).

Several studies have shown that risk behaviors do not occur separately, that is young people who report one risk behavior are likely to present others (Guilamo-Ramos, Litardo, \& Jaccard, 2005). This mutual relationship between risk behaviors was partially attributed to the decrease in exposure and risk perception (Pudney, 2003); for example, a teenager who smokes and drinks alcohol is associated with a subsequent illicit drug use (Wagner \& Anthony, 2002).

Parra and Oliva (2006) conducted a longitudinal study in which was found that parents' monitoring re- garding their children's behavior decreases between early adolescence and the end of this period. However, a strong association was found between both measurements indicating a high stability, that is, those adolescents who perceived increased monitoring in early adolescence were those who continued to experience a high monitoring at the end of this stage. While literature indicates that there are many factors that contribute the involvement of adolescents in some risk behaviors, background family factors along with the school and the community have significant effects on youth involvement in these behaviors (Oliva et al., 2008). Further, is reported that parental support is not associated with a delay in drinking initiation, but is associated with lower levels of later alcohol use (Ennett, Bauman, Foshee, Pemberton, \& Hicks, 2001; Jackson, Henriksen, \& Dickinson, 1999; Sieving, Maruyama, Williams, \& Perry, 2000).

One of the family factors associated with substance use (alcohol and illegal drugs) in young people is the effect of familiar environment and the genetic context. A poor family environment increases the risk of substance use and consumption problems in adolescence (Slomkowski et al, 2009; Wiesner, Weichold, \& Silbereisen, 2006). According to Schuckit (2009) this may reflect a combination of environmental and genetic influences. Nevertheless, empirical evidence has not been consistent because some studies report that the presence of alcoholism in family context is associated with alcohol consumption in youngness (Sher, Walitzer, Wood, \& Brent, 1991) while other studies have not found such relationship (Baer, Kiviahan, \& Marlatt, 1995).

Elliott, Carey and Bonafide (2012) made a meta-analysis to examine the effects of family drinking history in young people. The authors concluded that family history had significant (small to moderate) influence in the use of alcohol, as well as the involvement in illicit drug use. These findings support that family history concerning alcohol consumption is associated with alcohol problems rather than the consumption of it. Along these lines, Ryan, Jorm and Lubman (2010), conducted a review of several longitudinal studies on the factors associated with the onset and reduction of alcohol consumption in adolescents, where was found that parental modeling of drinking is associated with both earlier initiation to drinking and increased later alcohol use.

In this sense, the literature indicates that there is higher probability that alcoholic ingest in adolescence happens when the consumption of parents increase (Buelga \& Pons, 2004; Buelga, Ravenna, Musitu, \& Lila, 2006; Fromme \& Ruela, 1994; Villarreal, Sanchez-Sosa, Musitu, \& Varela, 2010). Generally, parents' alcohol consumption predisposes future consumption of their children al- 
though the existence of explicit verbal messages against its use (Varlinskaya, Spear, \& Spear, 2001).

Along these lines, parent-child relationship perceived with low support or conflictive, drive teenagers to low their self-regulation, and this is associated with a probably increase of alcohol consumption (Brody \& Ge, 2001). In addition, adolescents with low family support were frequently associated with deviant behavior friends (Wiesner et al., 2006). Furthermore, the evidence indicates that good parent-child relationship quality is associated with both delayed alcohol initiation and reduced levels of later alcohol use (Chuang, Ennett, Bauman, \& Foshee, 2005; Cohen, Richardson, \& LaBree, 1994; Jordan \& Lewis, 2005; Shortt, Hutchinson, Chapman, \& Toumbourou, 2007).

However, most studies are cross-sectional which complicate and determine whether these risk factors are concurrent with such conducts or as a result of them. Therefore it is important to elaborate longitudinal studies where is possible to keep track of the studied population to obtain a valid estimate of the problem in each measurement and to study the association between different risk factors over time (Samet \& Muñoz, 1998).

Thus the aim of this study was to analyze changes in risk behaviors in a group of students through a longitudinal study and determine the differences in family factors with the number to risk behavior (sexual conducts; tobacco, illegal drugs and alcohol consumption).

\section{Hypothesis}

The hypothesis of this research were:

$\mathrm{H}^{1}$ : There is an increase in the number of students who engage in risk behaviors with increasing age.

$\mathrm{H}^{2}$ : The amount of risk behaviors in which students engage tends to be higher with increasing age.

$\mathrm{H}^{3}$ : Students with fewer risk behaviors receive more support and better relationship within the family atmosphere in contrast to those who have a higher number of risk behaviors.

$\mathrm{H}^{4}$ : Students with fewer risk behaviors have fewer family members with substance use than those with a higher number of risk behaviors.

\section{METHOD}

\section{Participants}

It was an intentional non-probabilistic sample of 6089 students, $37.5 \%$ were male and $62.5 \%$ female; mean age at each measurement occasion were: 15.1 years $(S D=$ 1.15) first measurement, 18.0 years $(S D=1.13)$ second measurement, 22.1 years $(S D=1.16)$ last measurement.
The sample was obtained in a retrospective manner over seven years. Of the students spotted in their last year of their undergraduate studies (2010's school year), their information were tracked from the year they began their first bachelor year (2006's school year) and finally, when they started high school education (2003's school year). The number of participants which information was obtained at the beginning of high school was 17,670 youths; in the second measurement (at the beginning of the bachelors) the information of 11,489 adolescents was obtained, equivalent to $65 \%$ of the initial sample, the final sample $(6,089)$ corresponded to $34.45 \%$ of the initial sample. It should be noted that those students whose information could not be obtained $(65.54 \%$ of the initial sample) were not regular students and also were reported academic casualties.

\section{Measures}

For this study purposes, indicators of the Automated Medical Examination (EMA) were used to collect information on physical and mental health, family and environment in a student's sample of a public university in Mexico. Risk behaviors were assessed with 10 indicators. To evaluate sexual behavior, were asked three questions (3/10 indicators): presence of behavior, age of first intercourse and use of control birth method. Tobacco consumption was evaluated by the presence of behavior, age of first use and the number of cigarettes smoked per day (3/10 indicators). Alcohol consumption was evaluated with four questions (4/10 indicators) about the age of first use, frequency and quantity. With illegal drugs consumption, three questions that measured the presence of behavior, age of first use and type of illegal drug consumption were used.

Family support was evaluated with a five items likert scale with four response options measuring the adolescents perceptions about their family (responses never to always; $a=.834$ ). About the relationship between the student and the members of their family, a likert scale of three items with four response options (from very good to bad) was used, which evaluated the relationship of the young with parents and brothers $(a=.696)$. About health problems produced by alcohol and/or tobacco consumption in the members of the family (father, mother and siblings), a scale of six items was used with two response options (presence-absence) $(K R 20=.504)$.

\section{Procedure}

The application was conducted in group sessions. It was mentioned to the participants that the information they provide would be integrated into clinical records and that the use and administration of the same would be done 
according to the Mexican Official Standard on Health Record (Norma Oficial Mexicana NOM-004-SSA3-2012), which considers that the information contained in the clinical record will be handled with discretion and confidentiality, considering its use for medical actions, teaching and research. All the participants were invited to participate in the study via email, and it was mentioned that the study had a diagnostic purpose. The agreement from the legal tutor to allow the student to participate in the research was stated in an "acceptance of participation" document which should be printed, signed and handed the day of the application. For the following two evaluations, there was only a verbal agreement because the students were, already, in adult age.

\section{Statistical analysis}

Descriptive analysis was conducted to determine the participant's distribution in each risk behavior's indicator for the three measurements. In order to carry out the variance analysis, through Kolmogorov-Smirnov tests data was verified to have a normal distribution $(p>.05)$. In addition it was analyzed through Levene tests the homoscedasticity in its variances. This test were conducted in each variable and after fulfilling the necessary assumptions, analysis of variance for repeated measures were made in order to analyze the differences of risk behaviors and family factors between the three measurements. SPSS statistical package version 20 was used to carry out the statistical analysis.

\section{RESULTS}

A frequency analysis was done to determine the participant's distribution in each risk behaviors indicator for the three measurements (see Table 1). There is an important increase in the number of students who had begun their sexual life between the first measurement and the third one. In the third measurement, almost three-quarters of young people have had sex. The age of first sexual activity, is consistent with the date of measurement, i.e., in the first measurement, there was a higher percentage of students who reported sexual life initiation between 16 and 17 years old, and in the last one measurement -at the end of bachelor's degree- the highest percentage was concentrated after 17 years of age. Referring to the use of contraceptive methods, the three measurements indicated that condom is the most used, however, it is important to notice that the emergency pills are the second one (in all three measurements), above the contraceptive pills or injections.

On tobacco use, it was found an increase number of students who reported consumption in the third mea- surement, compared with the first one; at the last measurement, approximately one quarter of the sample reported a level of consumption. In terms of age of first tobacco use, the three measurements reported the highest percentages between 15 and 17 years old; similarly, the majority of youths reported smoking one to three cigarettes per day (see Table 1).

Concerning alcohol, the comparison of the students who reported alcohol consumption increased $200 \%$ from the first measurement to the third. In the first measurement, the consumption was around a quarter, and then in the third measurement it was three quarters of the total sample. Talking about the age of alcohol's first use, at the first measurement over a half of adolescents reported start consumption before 15 years old; for the other two measures, the highest percentage of age at first use was concentrated between 15 and 17 years old. About the frequency of consumption, in the two first measurements a larger number of students reported drinking alcohol between one and three times a year, and in the third measurement, the highest percentage of young people consumed at least once a month. In this sense, an important number of students reported consuming one to three drinks per occasion. Something remarkable is that the consumption of six or more drinks per time was not high in the first measurement, but it was the second reported in the second and third measurements (Table 1).

It was also found that illegal drugs consumption increased over time, from the first to the third measurement. Drug consumption over time -as well as the other risk behaviors-, reported an increase from the first to the third measurement, but despite of this, the number of youth who reported substances use is low. About the age of first use, in the first and second measurements there were a higher number of students who reported 15 and 17 years old as the age of first use, while in the third measurement the highest percentage was found in students who reported starting their consumption after 17 years old. As shown in Table 1, the most commonly illegal drug used was marijuana. Except for heroin, the substances reported an increment from the first measurement to the second one; however, in the third measuring these values decreased.

An indicator of presence-absence of each one of the risk behaviors was recorded in order to distinguish the students who did not present any risk behavior and those who presented the four risk behaviors (sexual behavior, tobacco consumption, alcohol consumption, use of illegal drugs) in the three measurements (Figure 1).

On the first measurement, almost half of students do not present risk behaviors and the proportion of youths who presented the fourth risk behaviors was low. The frequency of zero risk behaviors decrease over time, ac- 
Table 1

Percentage distribution of the participants in the indicators of the risk behavior in each one of the measurements

\begin{tabular}{|c|c|c|c|}
\hline & $\begin{array}{c}\text { Measurement } 1 \\
\%\end{array}$ & $\begin{array}{c}\text { Measurement } 2 \\
\%\end{array}$ & $\begin{array}{c}\text { Measurement } 3 \\
\%\end{array}$ \\
\hline Sexual behavior & $(n=6070)$ & $(n=6062)$ & $(n=6077)$ \\
\hline Yes & 6.6 & 39.4 & 74.6 \\
\hline No & 93.4 & 60.6 & 25.4 \\
\hline Age at first sexual activity & $(n=402)$ & $(n=2382)$ & $(n=4532)$ \\
\hline Before 15 years & 23.4 & 7.1 & 5.1 \\
\hline Between 15 and 17 & 50.0 & 58.5 & 33.6 \\
\hline After 17 years & 26.6 & 34.4 & 61.3 \\
\hline Contraceptive & $(n=368)$ & $(n=2315)$ & $(n=4508)$ \\
\hline Condom & 92.0 & 94.6 & 94.8 \\
\hline Emergency pills & 29.5 & 39.0 & 43.1 \\
\hline Pills or injections & 22.0 & 23.4 & 22.6 \\
\hline Others & 8.1 & 9.5 & 10.0 \\
\hline IUD & 2.0 & 3.8 & 5.9 \\
\hline Tobacco & $(n=6078)$ & $(n=6064)$ & $(n=6068)$ \\
\hline Yes & 5.8 & 21.4 & 25.7 \\
\hline Once, but no longer & 25.6 & 22.9 & 21.4 \\
\hline Do not consume & 68.6 & 55.7 & 52.9 \\
\hline Age of first use of tobacco & $(n=560)$ & $(n=2665)$ & $(n=2589)$ \\
\hline Before 15 years & 42.5 & 16.3 & 12.7 \\
\hline Between 15 and 17 & 46.8 & 64.4 & 48.4 \\
\hline After 17 years & 10.7 & 19.3 & 38.9 \\
\hline Daily smoking & $(n=488)$ & $(n=2349)$ & $(n=2484)$ \\
\hline 1 to 3 cigars & 90.4 & 88.9 & 85.7 \\
\hline 4 to 9 cigars & 8.2 & 9.9 & 12.8 \\
\hline 10 or more cigarettes & 1.4 & 1.2 & 1.5 \\
\hline Alcohol & $(n=5998)$ & $(n=6048)$ & $(n=6068)$ \\
\hline Yes & 24.0 & 64.1 & 79.6 \\
\hline Once, but no longer & 19.4 & 8.0 & 5.2 \\
\hline Do not consume & 56.6 & 27.9 & 15.2 \\
\hline
\end{tabular}


Table 1 (continued)

Percentage distribution of the participants in the indicators of the risk behavior in each one of the measurements

\begin{tabular}{|c|c|c|c|}
\hline & $\begin{array}{c}\text { Measurement } 1 \\
\%\end{array}$ & $\begin{array}{c}\text { Measurement } 2 \\
\%\end{array}$ & $\begin{array}{c}\text { Measurement } 3 \\
\%\end{array}$ \\
\hline Age of first use of alcohol & $(n=1552)$ & $(n=4361)$ & $(n=5152)$ \\
\hline Before 15 years & 53.1 & 16.9 & 11.3 \\
\hline Between 15 and 17 & 39.2 & 63.5 & 45.8 \\
\hline After 17 years & 7.7 & 19.6 & 42.9 \\
\hline Frequency of alcohol consumption & $(n=1547)$ & $(n=4337)$ & $(n=5136)$ \\
\hline From 1 to 3 times a year & 67.3 & 49.7 & 36.7 \\
\hline Once a month & 25.9 & 36.3 & 39.0 \\
\hline Once a week & 6.6 & 13.3 & 22.7 \\
\hline 3 or more times a week & .2 & .7 & 1.6 \\
\hline Quantity of alcohol & $(n=1543)$ & $(n=4338)$ & $(n=5137)$ \\
\hline From 1-3 drinks per occasion & 79.1 & 66.9 & 64.9 \\
\hline From 4-5 drinks per occasion & 14.8 & 22.7 & 24.0 \\
\hline 6 more drinks per occasion & 6.1 & 10.4 & 11.1 \\
\hline Illegal drugs & $(n=6031)$ & $(n=6052)$ & $(n=6076)$ \\
\hline Yes & .1 & .8 & 1.7 \\
\hline Once, but no longer & 1.2 & 6.4 & 10.0 \\
\hline Do not consume & 98.6 & 92.7 & 88.3 \\
\hline Age of first use of illegal drugs & $(n=51)$ & $(n=436)$ & $(n=718)$ \\
\hline Before 15 years & 21.6 & 4.8 & 2.6 \\
\hline Between 15 and 17 & 52.9 & 63.8 & 38.7 \\
\hline After 17 years & 25.5 & 31.4 & 58.6 \\
\hline Used drugs & $(n=51)$ & $(n=436)$ & $(n=718)$ \\
\hline Marijuana & 23.8 & 71.9 & 57.0 \\
\hline Hallucinogens & 4.0 & 8.1 & 6.8 \\
\hline Amphetamines & 3.3 & 7.0 & 5.1 \\
\hline Cocaine & 2.0 & 10.6 & 6.8 \\
\hline Inhalants & 2.0 & 6.7 & 2.3 \\
\hline Heroin & .7 & .2 & .7 \\
\hline
\end{tabular}


cording to the increase of risk behaviors. For the second measurement (when the students were at the beginning of their degree), a high percentage of students reported only one or two risk behaviors while a low percentage presented all of them. Finally, in the third measurement (before graduating), the highest proportion of students was regrouped on those who reported having two and three risk behaviors; although the proportion of youth with the four behaviors was low, this percentage was higher than in the two previous measurements.

In order to analyze the differences of risk behaviors between the three measurements, an analysis of variance for repeated measures was used. The results showed significant differences $[F(1.5868)=19205.93, p<.001]$ on teenagers scored in the first measurement with fewer risk behaviors $(M=.82, S D=.95)$, followed by second measurement $(M=1.40, S D=.99)$ and those who scored highest in the third measurement $(M=2.18, S D=1.07)$.

With regard to family factors, an analysis of variance for repeated measures was used to analyze the differences of risk behaviors between the three measurements (see Table 2). Significant differences were found in family relationship perception and in the number of family members who use substances. Students perceived a better family relationship in the first measurement compared with the subsequent measurements, whose scores were very similar. Also, the findings indicate an increase of substance use within family context from the first measurement to the following, with constant scores.

To analyze differences in family factors by the number of risk behaviors presented, a variance analysis was conducted for each of the three measurements. As shown in Table 3, significant differences were found in the three family factors on the three measurements. Scheffe post hoc tests indicate that students without or with just one risk behavior, scored significantly higher on family support and relationship than those who had two or more risk behaviors. Regarding family consumption, the results of the post hoc tests indicated, contrary to the other variables, that young people without or with just one risk behavior, scored significantly lower than those who had two or more risk behaviors. All these results were consistent in all three measurements.

\section{DISCUSSION}

The main purpose of this research was to analyze risk behaviors in a group of students through a longitudinal

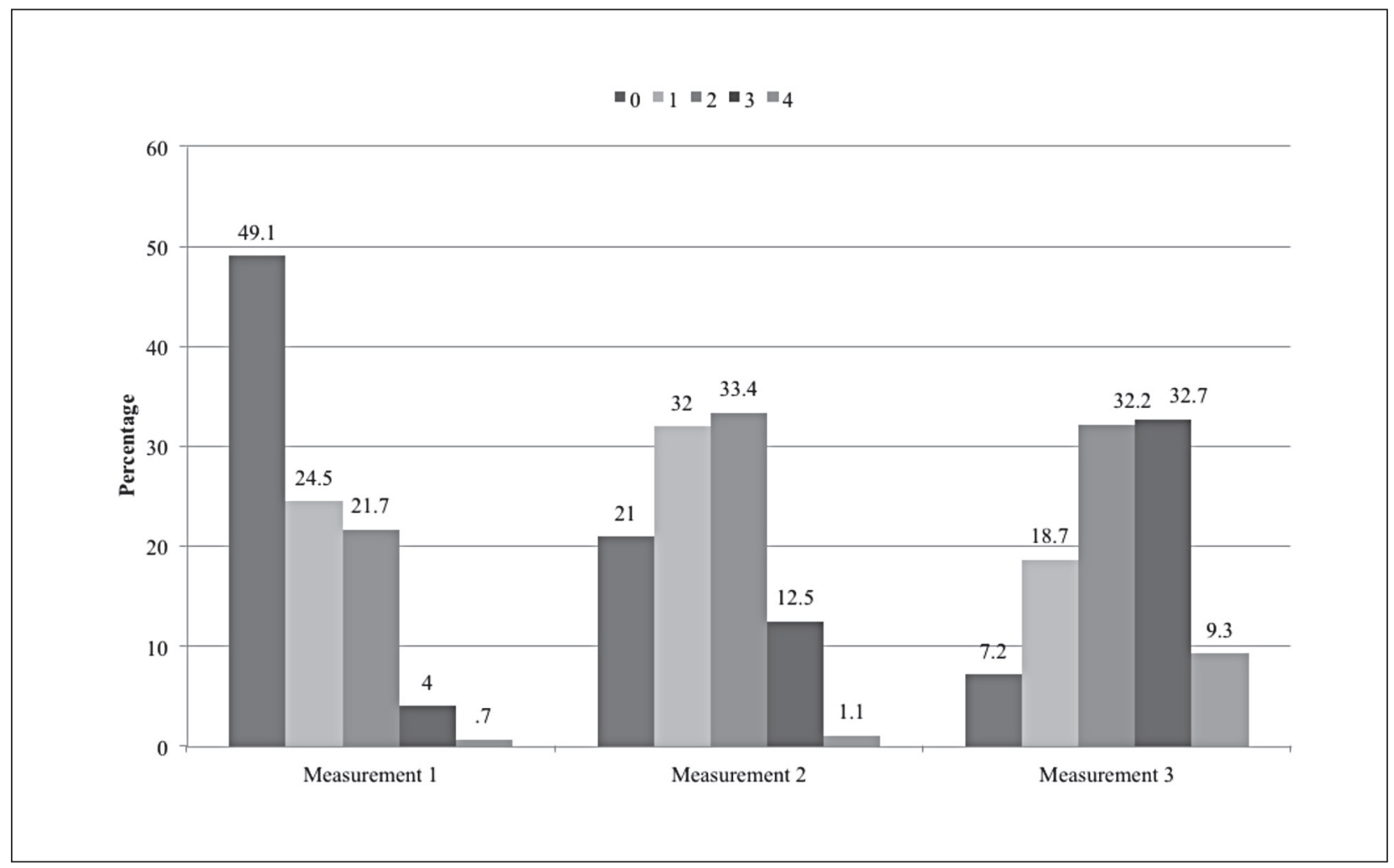

Figure 1. Number of risk behaviors in the three measurements 
Table 2

Family factors in the three measurements

\begin{tabular}{|c|c|c|c|c|c|c|c|}
\hline & \multicolumn{2}{|c|}{ Measurement 1} & \multicolumn{2}{|c|}{ Measurement 2} & \multicolumn{2}{|c|}{ Measurement 3} & \multirow[b]{2}{*}{$F$} \\
\hline & $M$ & $S D$ & $M$ & $S D$ & M & $S D$ & \\
\hline Family support & 10.70 & 3.02 & 10.00 & 2.72 & 10.11 & 3.40 & 1.25 \\
\hline Family relationship & 7.46 & 1.41 & 7.24 & 1.49 & 7.26 & 1.58 & $179.61^{* *}$ \\
\hline Family consumption & .39 & .71 & .54 & .84 & .56 & .86 & $332.14^{* *}$ \\
\hline
\end{tabular}

study and determine differences in family factors and risk behaviors (sexual behavior, consumption of tobac$\mathrm{co}$, alcohol and illegal drugs). Our first hypothesis were ratified, the findings show that there is an increase in the number of students who engage in risk behaviors with the increasing age. Likewise, it was shown that there is an increase in the amount of risk behaviors in which students engage as the age increases confirming the second hypothesis. Furthermore, students who received more family support and had better family relationship showed fewer risk behaviors. Finally, the fourth hypothesis in which students with fewer risk behaviors have fewer family members with substance use than those with a higher number of risk behaviors, has been confirmed.

Accordingly with ENA (INPRFM, INSP, \& SS, 2012c; INPRFM, INSP, \& SS, 2012a) we found that a greater number of young people used legal substances (tobacco and alcohol). Interestingly, this consumption was higher in the second and the third measurements. Trucco, Colder and Wieczorek (2011) suggested that there is a higher probability of legal substances consumption if these behaviors were approved and promoted by their pairs (Ali \& Dwyer, 2010; Rawana \& Ames, 2012). We did not consider this factor in the present study because of the need of evaluate either the quantity and/or the frequency of pair consumption. Another explanation of the increment in consumption might be related to the age of participants at every measurement. The mean ages for each application were 15 years old for the first; 18 for the second and 22 years for the third, which means that the students were already adults and they could buy legal substances by themselves.

Concerning the consumption of illegal drugs, our data showed similar percentages than national data on young consumers (INPRFM, INSP, \& SS, 2012b). Indeed, there was also an increase between measurements. The number of young people whom reported consuming any illegal drugs (data from the first and the second measurements) was lower than that reported by the ENA 2011
(1.5\%) in teenager population. However, in the third measurement our results $(1.7 \%)$ increased compared with the previous measurements and were not different to what has been reported by the ENA 2011. It is important to mention that the consumption of illegal drugs on the third measurement was two-fold greater than the reported on the second measurement, this question should be addressed in future studies.

Another relevant result found, was the kind of illegal drug use reported. National data indicated that the three most preferred illegal drugs are marijuana, followed by cocaine and hallucinogens sharing place with inhalants (INPRFM, INSP, \& SS, 2012b). Accordingly, here we found that marijuana was the most used drug in all the measurements followed, as well, by cocaine. In contrast, and contrary to what could be expected, the use of hallucinogens was greater than the inhalants. We can explain this result because our subjects were high education students and also belong to only one institution, in comparison with the general population taken by the ENA 2011. Further, we also found an increase in consumption on the second measurement compared to the first and third test, for each drug. We do not have a real explanation but can be speculated that this increase could response to the search and experimentation with different drugs by the subjects. This data behavior did not occur in the case of heroin: in the second and third measurements, the use of heroin decreased.

Family plays an important role in the different stages of adolescents, providing them with necessary tools for subsequent inclusion in the social and academic world. On this, the findings of this study showed that students perceived a better relationship within the family context in the first measurement than in the subsequent, which may differ from results presented by other authors (Holmbeck \& Hill, 1991; Oliva, 2006; Paikoff \& Brooks-Gunn, 1991) who explain that in the first part of adolescence, regular and major conflicts arise within the parent-child relationship and, as the children's age increases, this relationship becomes more stable. 


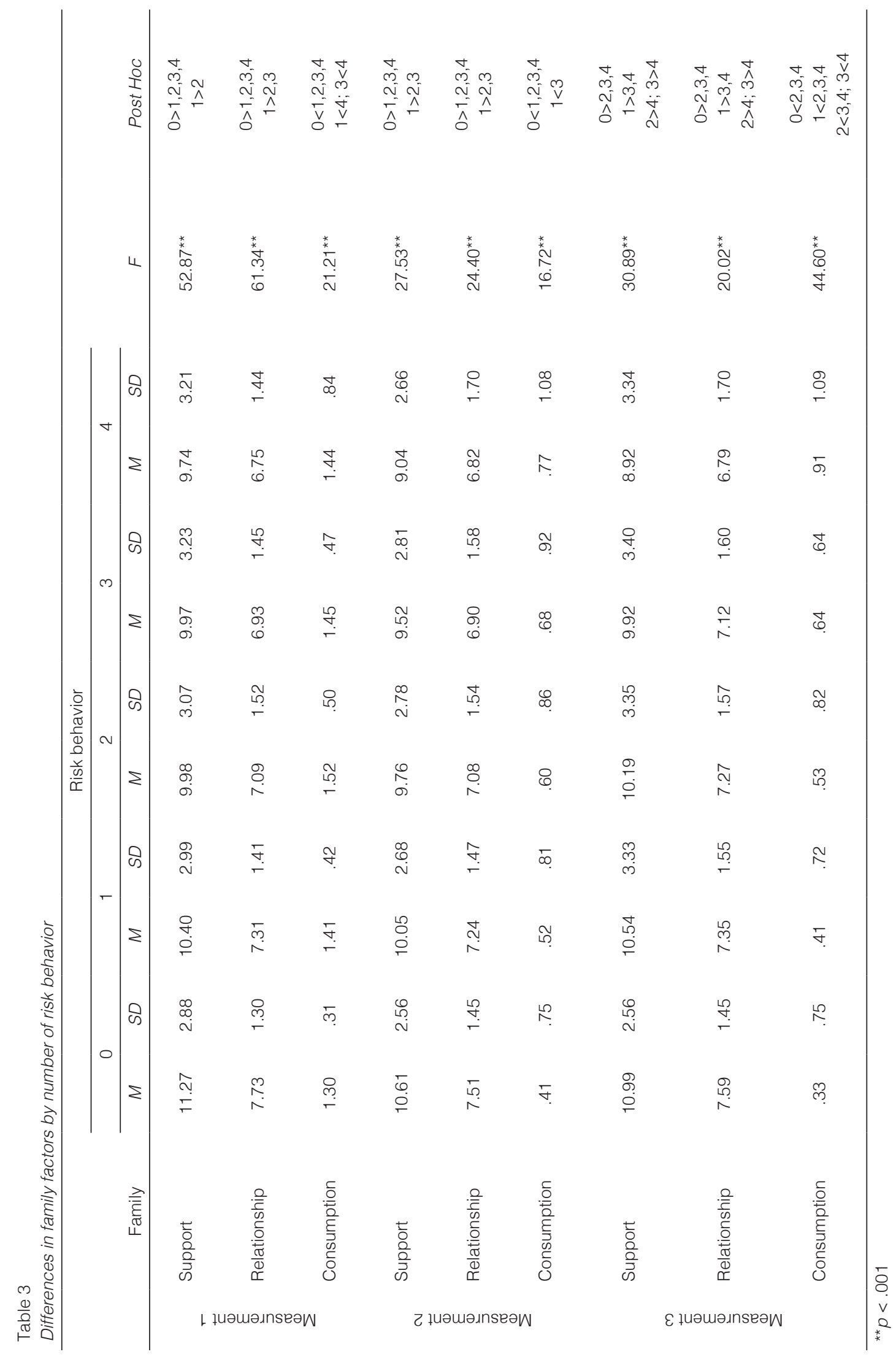


On the matter of substance use in the family context and its role in involving risk behaviors of adolescents, previous data is not entirely consistent (Baer et al., 1995; Buelga \& Pons, 2004; Buelga et al., 2006; Fromme \& Ruela, 1994; Sher et al., 1991; Varlinskaya et al., 2001; Villarreal et al, 2010). Elliott et al., (2012) conducted a meta-analysis and concluded that the history of household consumption has a small, but significant, effect on alcohol and other substances use in student population. More specifically, the authors suggest that the history of household consumption was more associated with substance use problems rather than the consumption itself. Here we found data about consumption and not about consumption problems, therefore those studies partially support our findings. In addition, significant differences were found among young people who have not been involved in risk behaviors and those who have been involved in some risk behaviors.

Moreover, our findings showed that substance abuse, by any member of the family, is associated with the involvement in risk behaviors, consistent with other reports (Ryan et al., 2010). In short, the above results prove hypothesis 3 and 4 , as they show that students who had fewer risk behaviors perceive more family support and better family value and also reported fewer family members who use substances, in contrast to those having more risk behaviors.

As limitations for the present study we could mention the following. First of all, it is difficult to generalize the data obtained to a representative population because our participants were part of a unique educational institution, despite the number of participants analyzed. Secondly, it would be necessary to standardize the instruments in a more general population. And third, since the participants could be identified by their student number this could bias the results obtained.

Until now, no data has been found on risk behaviors on a longitudinal study, therefore one advantage of the present study was the examination of the evolution and trajectories of a group of adolescents regarding the presence of various risk behaviors and the analysis in the relations with family factors over time. It is important to continue with the realization of this type of research, either to confirm these findings or to include some other variables as part of the possible risks for teenagers throughout their development.

Finally, altogether, this evidence will allow the development of prevention and early detection programs to treat several problems related to teenagers during their school period. Specially, considering as a great advantage having a captive population in a specific context, posing also a challenge and the possibility to, effectively, influence their development.

\section{FUNDING}

This research did not count on any funding type.

\section{CONFLICT OF INTEREST}

The authors state that there is no conflict of interest regarding this study.

\section{REFERENCES}

Ali, M. M., \& Dwyer, D. S. (2010). Social network effects in alcohol consumption among adolescents. Addictive Behaviors, 35(4), 337-342. doi: 10.1016/j.addbeh.2009.12.002

Baer, J. S., Kiviahan, D. R., \& Marlatt, G. A. (1995). High-risk drinking across the transition from high school to college. Alcoholism: Clinical and Experimental Research, 19, 54-61. doi: 10.1111/ j.1530-0277.1995.tb01472.x

Brody, G. H., \& Ge, X. (2001). Linking parenting processes and self-regulation to psychological functioning and alcohol use during early adolescence. Journal of Family Psychology, 15(1), 82. doi: 10.1037/0893-3200.15.1.82

Buelga, S., \& Pons, J. (2004). Alcohol y adolescencia: ¿Cuál es el papel de la familia? Encuentros en Psicología Social, 2(1), 39-43.

Buelga, S., Ravenna, M., Musitu, G., \& Lila, M. (2006). Epidemiology and psychosocial risk factors associated with adolescents' drug consumption. In S. Jackson, \& L. Goossens (Eds.). Handbook of adolescent development (pp. 337-369). Hove, UK: Psychology Press.

Chuang, Y. C., Ennett, S. T., Bauman, K. E., \& Foshee, V. A. (2005). Neighborhood influences on adolescent cigarette and alcohol use: mediating effects through parent and peer behaviors. Journal of Health and Social Behavior, 46(2), 187-204. doi: 10.1177/002214650504600205

Cohen, D. A., Richardson, J., \& LaBree, L. (1994). Parenting behaviors and the onset of smoking and alcohol use: a longitudinal study. Pediatrics, 94(3), 368-375

Elliott, J. C., Carey, K. B., \& Bonafide, K. E. (2012). Does family history of alcohol problems influence college and university drinking or substance use? A meta-analytical review. Addiction, 107(10), 1774-1785. doi: 10.1111/j.1360-0443.2012.03903.x

Ennett, S. T., Bauman, K. E., Foshee, V. A., Pemberton, M., \& Hicks, K. A. (2001). Parent-child communication about adolescent tobacco and alcohol use: what do parents say and does it affect youth behavior?. Journal of Marriage and Family, 63(1), 48-62.

Fromme, K., \& Ruela, A. (1994). Mediators and moderators of young adults' drinking. Addiction, 89(1), 63-71. doi: 10.1111/j.13600443.1994.tb00850.x

Guilamo-Ramos, V., Litardo, H. A., \& Jaccard, J. (2005). Prevention programs for reducing problem behaviors: implications of the co-occurrence of problem behaviors in adolescence. Journal of Adolescent Health, 36(1), 82-86. doi: 10.1016/j.jadohealth. 2003.12.013 
Gutiérrez, J. P., Rivera-Dommarco, J., Shamah-Levy, T., Villalpando-Hernández, S., Franco, A., Cuevas-Nasu, L., ... Hernández-Ávila, M. (2012). Encuesta Nacional de Salud y Nutrición 2012. Resultados Nacionales. Cuernavaca, México: Instituto Nacional de Salud Pública. Recuperada de: http://ensanut.insp. mx/informes/ENSANUT2012ResultadosNacionales.pdf

Hines, A. R., \& Paulson, S. E. (2006). Parents' and teachers' perceptions of adolescent storm and stress: relations with parenting and teaching styles. Adolescence, 41(164), 597-614.

Holmbeck, G. N., \& Hill, J. P. (1991). Conflictive engagement, positive affect and menarche in families with seventh-grade girls. Child Development, 62(5), 1030-1048.

Instituto Nacional de Psiquiatría Ramón de la Fuente Muñiz, Instituto Nacional de Salud Pública, Secretaría de Salud. (2012a). Encuesta Nacional de Adicciones 2011: Reporte de Alcohol. Medina-Mora, M. E., Villatoro-Velázquez J. A., Fleiz-Bautista, C, Téllez-Rojo, M. M., Mendoza-Alvarado, L. R., Romero-Martínez, M., Gutiérrez-Reyes, J. P., Castro-Tinoco, M., Hernández-Ávila, M., Tena-Tamayo, C., Alvear-Sevilla, C. y Guisa-Cruz, V. México: Autor.

Instituto Nacional de Psiquiatría Ramón de la Fuente Muñiz, Instituto Nacional de Salud Pública, Secretaría de Salud. (2012b). Encuesta Nacional de Adicciones 2011: Reporte de Drogas. ViIlatoro-Velázquez, J. A., Medina-Mora, M. E., Fleiz-Bautista, C., Téllez-Rojo, M. M., Mendoza-Alvarado, L. R., Romero-Martínez, M., Gutiérrez-Reyes, J. P, Castro-Tinoco, M., Hernández-Ávila, M., Tena-Tamayo, C., Alvear Sevilla, C. y Guisa-Cruz, V. México: Autor.

Instituto Nacional de Psiquiatría Ramón de la Fuente Muñiz, Instituto Nacional de Salud Pública, Secretaría de Salud. (2012a). Encuesta Nacional de Adicciones 2011: Reporte de Tabaco. Reynales-Shigematsu, L. M., Guerrero-López, C. M., Lazcano-Ponce, E., Villatoro-Velázquez, J. A., Medina-Mora, M. E., Fleiz-Bautista, C., Téllez-Rojo, M. M., Mendoza-Alvarado, L. R., Romero-Martínez, M., Gutiérrez-Reyes, J. P., Castro-Tinoco, M., Hernández-Ávila, M., Tena-Tamayo, C., Alvear Sevilla, C. y Guisa-Cruz, V. México: Autor.

Jackson, C., Henriksen, L., \& Dickinson, D. (1999). Alcohol-specific socialization, parenting behaviors and alcohol use by children. Journal of Studies on Alcohol, 60(3), 362-367.

Jordan, L. C., \& Lewis, M. L. (2005). Paternal relationship quality as a protective factor: preventing alcohol use among African American adolescents. Journal of Black Psychology, 31(2), 152-171. doi: 10.1177/0095798405274881

Lerner, R. M. (2005, September). Promoting positive youth development: theoretical and empirical bases. In white paper prepared for the Workshop on the Science of Adolescent Health and Development, National Research Council/Institute of Medicine. Washington, DC: National Academies of Science.

Norma Oficial Mexicana NOM-004-SSA3-2012, del expediente clínico. (2012). México: Secretaría de Salud.

Oliva, A. (2006). Relaciones familiares y desarrollo adolescente. Anuario de Psicologia/ The UB Journal of Psychology, 37(3), 209-224.
Oliva, A., Hernando, A., Parra, A., Pertegal, M. A., Ríos, M., \& Antolín, A. (2008). La promoción del desarrollo adolescente: recursos y estrategias de intervención. Sevilla: Junta de Andalucía, Consejería de Salud.

Paikoff, R. L., \& Brooks-Gunn, J. (1991). Do parent-child relationships change during puberty? Psychological Bulletin, 110(1), 47. doi: 10.1037/0033-2909.110.1.47

Parra, A., \& Oliva, A. (2006). Un análisis longitudinal sobre las dimensiones relevantes del estilo parental durante la adolescencia. Infancia y Aprendizaje, 29(4), 453-470.

Pudney, S. (2003). The road to ruin? sequences of initiation to drugs and crime in Britain. The Economic Journal, 113(486), C182-C198. doi: 10.1111/1468-0297.00107

Rawana, J. S., \& Ames, M. E. (2012). Protective predictors of alcohol use trajectories among Canadian Aboriginal youth. Journal of Youth and Adolescence, 41(2), 229-243. doi: 10.1007/s10964011-9716-9

Ryan, S. M., Jorm, A. F., \& Lubman, D. I. (2010). Parenting factors associated with reduced adolescent alcohol use: a systematic review of longitudinal studies. Australian and New Zealand Journal of Psychiatry, 44(9), 774-783. doi: 10.1080/00048674.2010.501759

Samet, J. M., \& Muñoz, A. (1998). Evolution of the cohort study. Epidemiologic Reviews, 20(1), 1-14.

Schuckit, M. A. (2009). Alcohol-use disorders. The Lancet, 373(9662), 492-501. doi: 10.1016/S0140-6736(09)60009-X

Sher, K. J., Walitzer, K. S., Wood, P. K., \& Brent, E. E. (1991). Characteristics of children of alcoholics: putative risk factors, substance use and abuse, and psychopathology. Journal of Abnormal Psychology, 100(4), 427-448. doi: 10.1037/0021-843X.100.4.427

Shortt, A. L., Hutchinson, D. M., Chapman, R., \& Toumbourou, J. W. (2007). Family, school, peer and individual influences on early adolescent alcohol use: first-year impact of the Resilient Families programme. Drug and Alcohol Review, 26(6), 625-634. doi: 10.1080/09595230701613817

Sieving, R. E., Maruyama, G., Williams, C. L., \& Perry, C. L. (2000). Pathways to adolescent alcohol use: Potential mechanisms of parent influence. Journal of Research on Adolescence, 10(4), 489-514. doi: 10.1207/sjra1004_06

Slomkowski, C., Conger, K. J., Rende, R., Heylen, E., Little, W. M., Shebloski, B., ... \& Conger, R. D. (2009). Sibling contagion for drinking in adolescence: a micro process framework. International Journal of Developmental Science, 3(2), 161-174. doi: 10.3233/DEV-2009-3206

Trucco, E. M., Colder, C. R., \& Wieczorek, W. F. (2011). Vulnerability to peer influence: a moderated mediation study of early adolescent alcohol use initiation. Addictive Behaviors, 36(7), 729-736. doi: 10.1016/j.addbeh.2011.02.008

Varlinskaya, E. I., Spear, L. P., \& Spear, N. E. (2001). Acute effects of ethanol on behavior of adolescents rats: role of social context. Alcoholism Clinical and Experimental Research, 25(3), 377-385. doi: 10.1097/00000374-200103000-00009

Villarreal, M. E., Sánchez-Sosa, J. C., Musitu, G., \& Varela, R. (2010). El consumo de alcohol en adolescentes escolarizados: pro- 
puesta de un modelo sociocomunitario. Intervención Psicosocial, 19(3), 253-264.

Wagner, F. A., \& Anthony, J. C. (2002). Into the world of illegal drug use: exposure opportunity and other mechanisms linking the use of alcohol, tobacco, marijuana, and cocaine. American Journal of Epidemiology, 155(10), 918-925. doi:10.1093/aje/155.10.918

Wiesner, M., Weichold, K., \& Silbereisen, R. K. (2006). Trajectories of alcohol use among adolescent boys and girls: identification, validation, and sociodemographic characteristics. Psychology of Addictive Behaviors, 21(1), 62-75. doi: 10.1037/0893$164 \times .21 .1 .62$

Wijsbroek, S., Hale, W., Van Doorn, M., Raaijmaker, Q., \& Meeus, W. (2010). Is the resolution style 'exiting statements' related to adolescent problem behavior? Journal of Applied Developmental Psychology, 31, 60-69. doi: 10.1016/j.appdev.2009.08.002 